\title{
Viscometry determination of the kinetic of degradation of iron-gall inks
}

\author{
Michaela Ciglanská, Michal Čeppan \\ Slovak University of Technology in Bratislava, Faculty of Chemical and Food Technology, \\ Department of Graphic Art Technology and Applied Photochemistry, \\ Radlinského 9, 821 37, Bratislava, Slovakia \\ michaela.ciglanska@stuba.sk
}

\begin{abstract}
Degradation of historical written documents, drawings and manuscripts containing iron-gall inks is a significant problem for years. Many researches proved that iron (II) ions and acids in the iron-gall inks cause damage of these documents. The purpose of this study was to assess the possibility of using degree of polymerization based on viscometric data in study of kinetic of degradation and determination of kinetic constant of degradation of model systems iron-gall inks - paper substrate. The obtained results were compared to the results obtained using degrees of polymerization based on gel permeation chromatography data. It was found, that the kinetic constants of degradation of model systems obtained from viscometric and from gel permeation chromatography data correlate.
\end{abstract}

Keywords: iron-gall inks, degradation of historical documents, viscometry, gel permeation chromatography

\section{Introduction}

The iron-gall inks were used as the writing means from the Antique period to the middle of the last century (Budnar et al. 2006, Durovič 2002, Kolar et al. 2006). A lot of different written documents, drawings and manuscripts in which iron-gall inks were used can be found in many libraries, archives and museums worldwide. The iron-gall inks have been prepared according to a broad variety of recipes. The main components of the inks recipes were ferrous and copper sulphate, gallic acid and gum arabic. Unfortunately, these components cause severe damage or even complete destruction of historical artefacts due to the ink corrosion (Schölten 1997, Steemers 2006).

Main reasons of iron-gall inks corrosion are the acid hydrolysis of the glycosidic bonds and the cellulose oxidation (Ďurovič 2002, Wouters and Banik 2000). Acid hydrolysis is caused by the acids in the iron-gall inks and also by the sulfuric acid gradually formed during the curing of ink deposited on a paper substrate. Iron (II) ions are suspected to cause the oxidative degradation of cellulose by catalysing the formation of hydroxyl radicals $(\mathrm{HO} \bullet)$ from hydrogen peroxide in the Fenton reaction (Emery and Schroeder 1994, Walling 1975):

$$
\mathrm{Fe}(\mathrm{II})+\mathrm{H}_{2} \mathrm{O}_{2} \leftrightarrow \mathrm{Fe}(\mathrm{III})+\mathrm{HO} \bullet+\mathrm{OH}^{-}
$$

Hydrogen peroxide is formed during the reduction of molecular oxygen by iron (II) ions. Hydroxyl radicals are very reactive and readily abstract hydrogen from cellulose, leading to the formation of organic radicals $(\mathrm{R} \bullet)($ Neevel 2003).
In the present study, two methods for analyzing degradation of cellulose and influence of iron-gall inks on the ageing of cellulose were compared. The first method was viscometry, which is often the preferred method to estimate the average degree of polymerization (DP) of paper samples. This method is fast and convenient. The second method was the gel permeation chromatography (GPC). The both methods allow to determine the degree of polymerization and consequently to study the kinetic of degradation of iron-gall inks - substrate systems. The aim of the paper was to find out, if the correlation between rate constants of degradation of model systems iron-gall inks - paper substrate based on viscometry and GPC data exists.

\section{Experimental}

According to historical recipes of Neevel (Neevel 1975), we prepared two iron-gall inks (I1, I2) samples with the different ratios of $\mathrm{FeSO}_{4} \cdot 7 \mathrm{H}_{2} \mathrm{O}$ (Lachema) and gallic acid (Sigma-Aldrich) 0.25 and 4 respectively. The amount of other mean component, gum arabic (Sigma-Aldrich) - playing a role of suspension stabilizer and ink carrier, was kept constant $(7.85 \mathrm{~g} / 100 \mathrm{ml}$ of deionized water) in all inks.

Freshly prepared inks were treated in ultrasound basin for 10 minutes for maximum homogenity and then were kept in the dark for 7 days long. Consequently, model systems of iron-gall inks - substrate (WI1, WI2) with $\mathrm{pH} 3$ and $\mathrm{pH} 10$ for each irongall ink were prepared. As a substrate filter paper Whatman No. 1 (85 g.m²), which is consider to be a pure cotton linter cellulose, was used. Uniform 
application of the inks on the substrate $(5 \times 5 \mathrm{~cm})$ was obtained by immersion of the substrate into the inks samples. Soaked up samples of the paper were interposed between two filter papers and dried using a rubbery roller at a constant pressure.

The $\mathrm{pH}$ of model systems were modified using the standard acido-base agent $0.04 \mathrm{M} \mathrm{Mg}\left(\mathrm{HCO}_{3}\right)_{2}$. The samples were immersed into the properly diluted standard solutions for various times to obtain the $\mathrm{pH}$ values 3 and 10 .

As a third system the pure paper Whatman No. 1 without applied inks was used. The paper Whatman No. 1 itself has the $\mathrm{pH}$ value 6.82 . The $\mathrm{pH}$ value 3 was achieved treating the samples of paper with a damping solution $\left(0.2 \mathrm{M} \mathrm{Na}_{2} \mathrm{HPO}_{4}+0.1 \mathrm{M}\right.$ citric acid diluted in deionized water) and $\mathrm{pH}$ value 10 by using an alkaline solution $(0.04 \mathrm{M}$ $\mathrm{Mg}\left(\mathrm{HCO}_{3}\right)_{2}$ properly diluted in deionized water).

The samples were submitted to the thermal accelerated ageing in closed vessels according the standard ISO 5630-5 (ISO 2006). Samples were conditioned for 24 hours in a climatic room with temperature $23{ }^{\circ} \mathrm{C}$ and relative humidity of $50 \%$ in the opened special flasks with the volume of $130 \mathrm{~cm}^{3}$. After 24 hours all flasks were closed and put into the oven (multiple-function oven APT Line Series FED, Czech Republic). The samples were aged at temperature $100{ }^{\circ} \mathrm{C}$ for $1,4,8,16$ and 24 hours. The times of accelerated ageing for samples of paper Whatman without the inks were $1,4,8,16,24,96$, 120 and 192 hours.

Estimation of correspondence of time of thermal accelerated ageing with the amount of time of ageing under normal conditions is rather difficult because of two reasons. Such equivalence of time of accelerated ageing and the time of ageing under normal conditions was established only for accelerated ageing according to the standard ISO 5630-1 for dry heat treatment at $105^{\circ} \mathrm{C}$ (ISO 1999) and for the paper substrate only. Similar equivalence for the accelerated ageing according to the standard ISO 5630-5 for exposure to elevated temperature at $100{ }^{\circ} \mathrm{C}$ (ISO 2006) used in this study has not been established even not for a pure paper. So, few researchers estimated, that the 3 days of accelerated ageing at $105^{\circ} \mathrm{C}$ is equivalent to 25 years of natural ageing at $20^{\circ} \mathrm{C}\left(18^{\circ} \mathrm{C}\right)$ (Barrow 1963, Wilson et al. 1955).

The average degrees of polymerization of the aged samples were determined from viscometric and from GPC data. Viscometry measurements were realized in the capillary viscometer (UNITEX viscometer for the determination of the cellulose polymerization, Effeci di Vincenzo Formenti, Italy; complying to the standard ISO 5351-1 for determination of limiting viscosity number of cellulose (ISO 1994)). The procedure, solvent (cupriethylenediamine (CED, Sigma-Aldrich)) and calculations according to the standard ISO 5351-1 (ISO 1994) were followed and the constants and the parameters data listed in tables of this standard were used in the calculations. Degrees of polymerization were calculated from the intrinsic viscosity data using Mark-HouwingSakurada equation and the constants according to Evans and Willis (Evans and Wallis 1987, Kolar and Strlic 2004). The rate constants of degradation of samples " $k$ " were calculated using the Ekenstam equation (Ekenstam 1936):

$$
1 / D P=\left(1 / D P_{0}\right)+k t
$$

where $D P=$ degree of polymerization after ageing, $D P_{0}=$ degree of polymerization at the beginning of ageing, $k=$ rate constant of degradation $\left[\mathrm{h}^{-1}\right]$, $t=$ time of ageing $[\mathrm{h}]$.

The gel permeation chromatography (GPC) is a type of liquid chromatography and allows us to characterize different average molecular weights such as the number molecular weight $\left(M_{n}\right)$ and the weight molecular weight $\left(M_{w}\right)$.

The degrees of polymerization of all samples were determined also from the gel permeation chromatography (GPC) data using the equation (Halajová and Kačík 2011, Kačík et al. 2009):

$$
D P=M_{w} / 162
$$

where $M_{w}$ is the average molecular weight from GPC data. As in the previous case the rate constant of degradation " $k$ " was calculated from $D P$ using the Ekenstam equation (2).

\section{GPC method}

The following parameters were used in the GPC measurements - flow: $1.00 \mathrm{~mL} / \mathrm{min}$; columns: four PL gel mixed ALS, $20 \mu \mathrm{m}, 7.5 \times 300 \mathrm{~mm}$; injection volume: $100 \mu \mathrm{L}$; run time: $45 \mathrm{~min}$; mobile phase: DMAc/LiCl $(0.9 \%$, w/v) filtered through a $0.02 \mu \mathrm{m}$ filter.

The samples were dissolved in the solution of DMAc/LiCl.

\section{Results and discussion}

Fig. 1, 2 show the dependence of the degree of polymerization (DP) on the time of accelerated ageing for the system iron-gall ink - Whatman (WI1) with pH 3 and pH 10. Degradation curves obtained from viscometric and GPC data respectively differs. The degrees of polymerization based on viscometric data are in most cases higher (or not significantly greater) than the corresponding degrees of polymerization based on GPC data. The situation was the same for the degradation lines of the other samples. 
One of the possible explanations of this difference is that the used constants of Mark-Houwing-Sakurada equation for calculation of degrees of polymerization according to Evans and Willis were determined for pure cellulose and thus the hydrodynamic conditions in viscometer should correspond to the dissolved pure cellulose. Samples of the systems iron-gall ink - paper Whatman create slightly different hydrodynamic conditions in viscometer, what leads to the different absolute values of the measured degrees of polymerization. Another reason of difference can be attributed to different solvents used in respective methods.

The rate constants of degradation of the model systems iron-gall inks - paper Whatman (WI1, WI2) and pure paper Whatman (W) in the region $\mathrm{pH}$ 3 and pH 10 obtained using two methods, viscometry and gel permeation chromatography, are on the Fig. 3 and 4. Although the values of rate constants

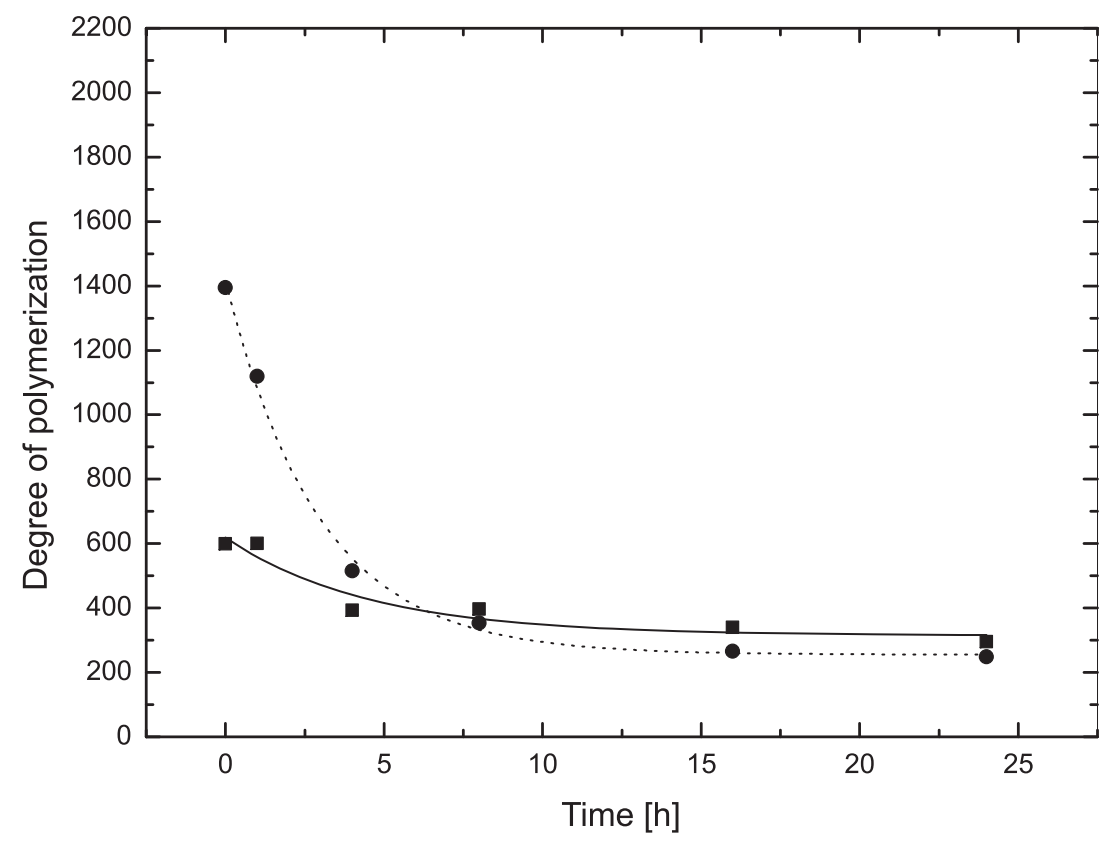

Fig. 1. Degradation curves (degrees of polymerization determined viscometrically and from GPC data); model system WI1 - Whatman; iron-gall ink Fe(II):gallic acid = 0.25; pH 3, (GPC: solid squares, solid line; viscometry: solid circles, dot line).

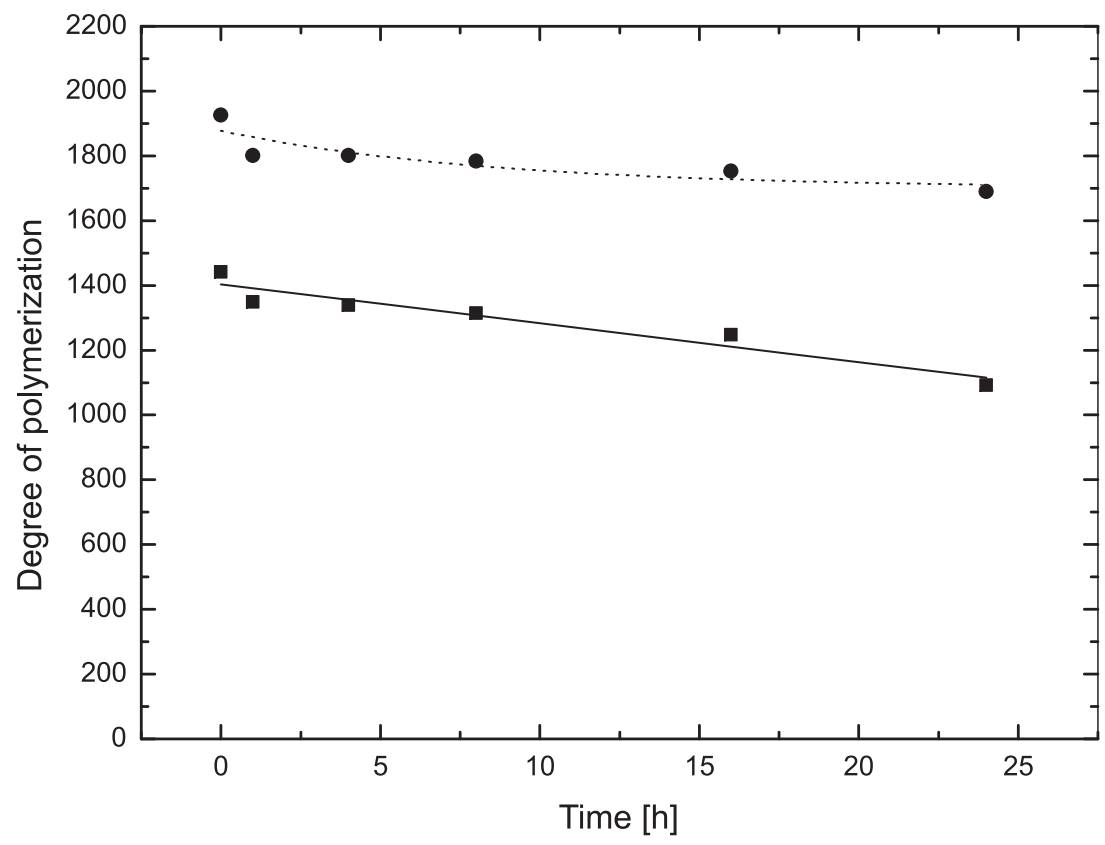

Fig. 2. Degradation curves (degrees of polymerization determined viscometrically and from GPC data); model system WI1 - Whatman; iron-gall ink Fe(II):gallic acid = 0.25; pH 10, ((GPC: solid squares, solid line; viscometry: solid circles, dot line). 


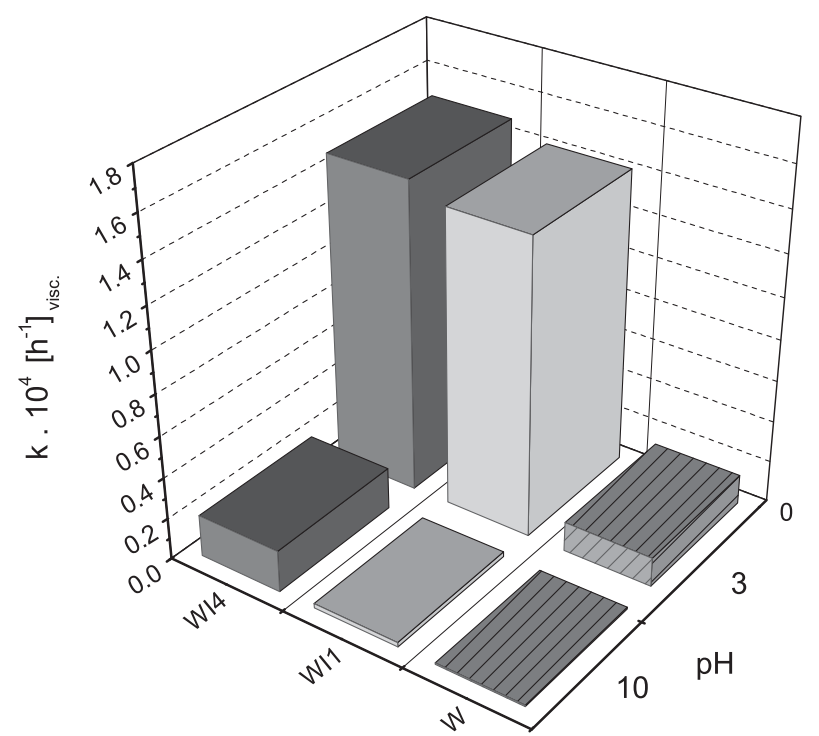

Fig. 3. The rate constants of degradation, viscometry; paper Whatman No. 1 (W), model systems (WI1, WI2), pH 3 and pH 10.

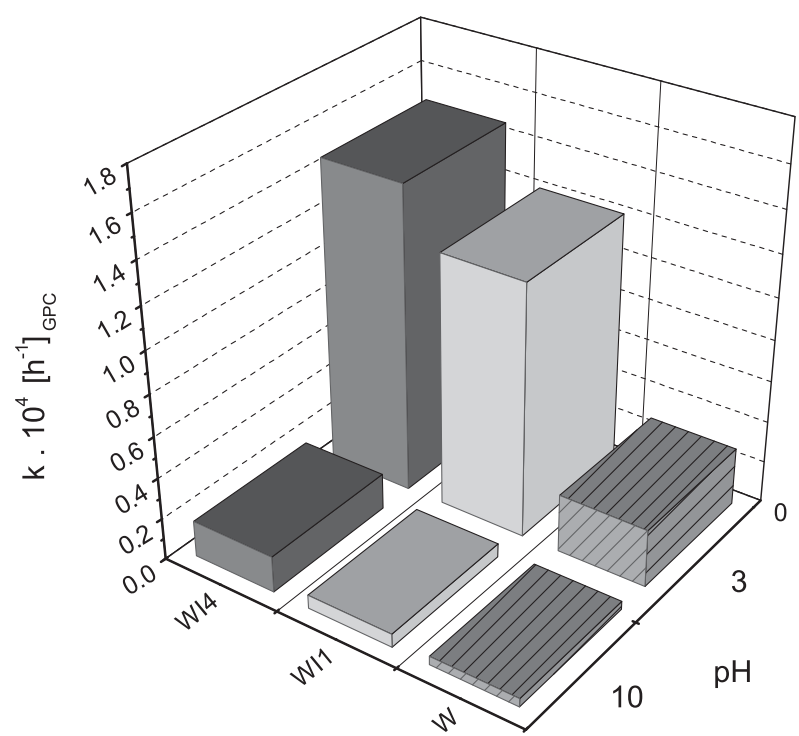

Fig. 4. The rate constants of degradation, GPC; paper Whatman No. 1 (W), model systems (WI1, WI2), pH 3 and pH 10.

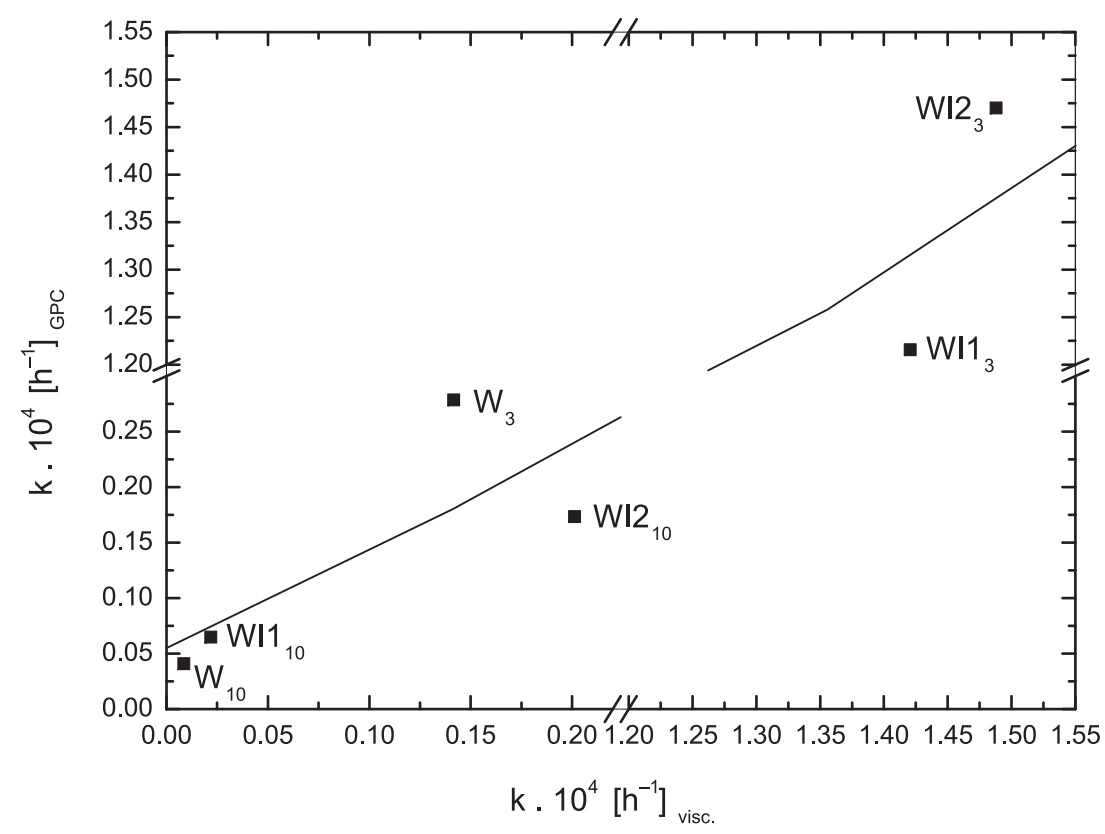

Fig. 5. Dependence of the rate constants of GPC on the rate constants of viscometry; paper Whatman No. 1 (W), model systems (WI1, WI2), pH 3 and pH 10.

obtained by these methods are not equal, both sets of rate constants follow the same general trends: the rate of degradation of all samples is higher in the acid region $\mathrm{pH} 3$ comparing to the alkaline region pH 10; the rate of degradation of samples containing iron-gall inks is higher comparing to the rate of degradation of pure substrate and depends on the composition of the inks, this behavior is more significant in the acid region.

The correlation of the rate constants of degradation of studied samples determined viscometric and the rate constants based on GPC data is on the
Fig. 5. The correlation is linear with the coefficient of correlation 0.99 .

\section{Conclusions}

The study deals with the comparison rate constants of degradation of model systems iron-gall ink - paper substrate using two methods for determination of degrees of polymerization: viscometry and gel permeation chromatography.

The results obtained in this study demonstrates, that the kinetic constants of degradation of systems 
iron-gall ink - paper substrate obtained from degradation curves based on viscometric data and GPC data correlate. Thus, the simpler viscometric method of determination of degree of polymerization can be used in study of kinetic of degradation model samples of systems iron-gall ink - paper substrate.

This finding corresponds to the conclusion of the study of correlation between viscometrically determined degrees of polymerization and Mw determined from GPC data for carbanilated cellulose (Kolar et al. 2006).

\section{Acknowledgement}

This work was supported by courtesy of the Slovak Grant Agency (VEGA 1/0800/08). We would like to thank Silvia Candráková for valuable assistance. The GPC analysis was sponsored by a scholarship grant by the Aktion Österreich-Slowakei (ICM-2011-00501). We would like to thank Univ. Ass. Dipl. Rest. Dr. nat. techn. Ute Henniges and Ao. Univ. Prof. Dipl. - Chem. Dr. rer. nat. Antje Potthast for valuable assistance on University of Natural Resources and Life Sciences, Vienna, Austria.

\section{References}

Barrow WJ (1963) Permanence/Durability of the Book. A Two-year Research Program. W. J. Barrow Research Laboratories, Richmond.

Budnar M, Uršiš M, Simčič J, Pelicon P, Kolar J, Šelih VS, Strlič M (2006) Analysis of iron gall inks by PIXE, Nuclear Instruments and Methods in Physics Research B 243: 407-416.

Durovič M (2002) Restaurování a konzervování archiváliî a knih (Restauration and Conservation of Archivals and Books), Paseka, Prague.

Ekenstam A (1936) Über das Verhalten der Cellulose in Mineralsäure-Lösungen, II. Mitteil.: Kinetisches Studium des Abbaus der Cellulose in Säure-Lösungen, Ber. 69: 553.

Emery JA, Schroeder HA (1994) Iron-Catalyzed Oxidation of Wood Carbohydrates, Wood Science and Technology 8: 123-137.

Evans R, Wallis AFA (1987) Proceedeings $4^{\text {th }}$ Int. Symp. Wood Chem.: 201.

Halajová L, Kačík F (2011) Vplyv urýchleného starnutia na degradáciu recyklovaných buničín: čast̉ 1: Teplota sušenia $100{ }^{\circ} \mathrm{C}$ (Influence of accelerated ageing on degradation of the recycled pulps: part 1: Temperature of dying $100{ }^{\circ} \mathrm{C}$ ), Acta Facultatis Xylologiae Zvolen 53 (1): 63-67.

ISO 5351-1 (1994) Cellulose in dilute solutions Determination of limiting viscosity number, Part 1: Method in cupri-ethylene-diamine (CED) solution.

ISO 5630-1 (1999) Paper and board - Accelerated ageing, Part 1: Dry heat treatment at $105^{\circ} \mathrm{C}$.

ISO 5630-5 (2006) Paper and board - Accelerated ageing, Part 5: Exposure to elevated temperature at $100{ }^{\circ} \mathrm{C}$.

Kačík F, Geffertová J, Kačíková D (2009) Charakterizácia celulózy a buničín metódou gélovej permeačnej chromatografie a viskozimetrie (Characterization of cellulose and pulps by the methods of gel permeation chromatography and viscometry), Acta Facultatis Xylologiae Zvolen 51(2): 93-103.

Kolar J, Strlič M (2004) Restaurator 23: 94.

Kolar J, Strlič M, Balažic A, Kočar D (2006) Determination of molar mass of cellulose in historical documents, in: 2nd International Iron Gall Ink Meeting, PreConference Proceedings, TNO: 90-92.

Kolar J, Stolfa A, Strlič M, Pompe M, Pihlar B, Budnar M, Simčič J, Reissland B (2006) Historical iron gall ink containing documents - Properties affecting their condition, Analytica Chimica Acta 555: 167-174.

Neevel JG (1975) Restaurator 16: 143.

Neevel JG (2003) The Development of a New Conservation Treatment for Ink Corrosion, Based on the Natural Anti-oxidant Phytate, http://cool.conservation-us.org/ iada/ta95_093.pdf, available at 6. 5. 2011.

Schölten S. In: Windt HVD (1997) Proceedings of the European workshop on iron-gall ink corrosion. Amsterdam: Instituut Collectie Nederland: 9-12.

Steemers T: Damage survey of archives containing iron gall inks. In: Kolar J, Strlič M (2006) Iron gall inks: on manufacture, characterisation, degradation and stabilisation. Ljubljana: National and University Library: 20-24.

Walling Ch (1975) Fenton's Reagent Revisited, Accounts of Chemical Research 8: 125-131.

Wilson WK, Harvey JL, Mandel J, Worksman T (1955) Accelerated Aging of Record Papers Compared with Normal Aging. Tappi 38 (9): 543-548.

Wouters J, Banik G (2000) Inks from the Middle Ages: Old Recipes, Modern Analysis and Future Decay, Christine Van den Bergen-Pantens (Ed.), Les Chroniques De Hainaut, Ou Les Ambitions D'Un Prince Bouguignon, Brepols publishers, Turnhout: 141-148. 